because of their complete setting and low acid content. When thoroughly dried by baking at high temperatures, they are no longer thermoplastic. This allows coils to operate at higher temperatures without softening the impregnating material and permits substantial savings by reducing the size of the coils. The penetrating power of these synthetic resins and their high dielectric strength make them particularly valuable for high-voltage circuits where corona discharges might occur and, by oxidizing the nitrogen, produce nitric acid which breaks down the coil insulation. Retardation coils and power transformers of several types, designed for telephone apparatus, are now being impregnated on a production basis with synthetic resin varnishes. The results indicate advantageous possibilities for their wider use.

\section{Tuberculosis Control in Argentina}

According to Dr. Hugo J. D'Amato, secretary of the National Department of Health of Argentina (Bol. Of. San. Panamer., 21, 772; 1942), family contacts have been examined in the last few years at the tuberculosis dispensaries of this department in order to discover unrecognized cases. As this procedure, however, did not include extra-familial contacts a new organization is being planned which will involve systematic and repeated examinations of the entire population. At present all public employees and all applicants for Government positions have to undergo clinical and radiological examinations of the thorax as well as tuberculin tests. Of 10,863 persons examined 104 were rejected and $5 \mathrm{I}$ were accepted with a temporary certificate while under treatment. Only six of the 10,708 applicants declared to be healthy or 60 per 100,000 have developed tuberculosis in the course of two years, whereas before examination was made compulsory the rate of infection was 520 per 100,000. In August 1941 the National Commission of Tuberculosis was created, which besides centralizing the administration of the tuberculosis control campaign, has power to propose measures regarding salaries, housing, nutrition and industrial hygiene.

\section{Earthquakes Registered in Switzerland}

During July and August 1942, thirty earthquakes were registered by the instruments at the Swiss observatories of Zurich, Chur, Basel and Neuchâtel (Swiss Earthquake Bull., No. 146 and No. 147). The distant earthquakes have, for the most part, been mentioned previously in the columns of NaTURE, but the local earthquakes have not. On July 1 an earthquake was felt with intensity $V$ (Rossi-Forel scale) in the Pays d'Enhaut. It was registered at Zurich at $23 \mathrm{~h} .43 \mathrm{~m} .13 \cdot 3 \mathrm{~s}$., the epicentre being some $135 \mathrm{~km}$. distant. On July 17 an earthquake was registered at Chur at $10 \mathrm{~h} .27 \mathrm{~m} .08 \cdot 8 \mathrm{~s}$., which had its epicentre in the Schwäbische Alb, and on July 18 an earthquake registered at Basel at $15 \mathrm{~h} .46 \mathrm{~m}$. $08 \cdot 3 \mathrm{~s}$. had its epicentre less than $10 \mathrm{~km}$. to the north-west of that station. The earthquake of August 27, registered at Zurich at $11 \mathrm{~h} .11 \mathrm{~m} .21 .9 \mathrm{~s}$. , had its epicentre $70 \mathrm{~km}$. from that station and was felt in the neighbourhood of the Brünig and Lungernsee. Finally, the earthquake of August 28, registered at Zurich at $11 \mathrm{~h} .28 \mathrm{~m} .58 \cdot 4 \mathrm{~s}$, had its epicentre $71 \mathrm{~km}$. from that place and was felt with intensity $\mathrm{V}$ in the neighbourhood of the Hohenstollen.

\section{An Important Binary Star System}

Dr. R. M. Petrie, of the Dominion Astrophysical Observatory, Victoria, B.C., reports the discovery of another sub-dwarf star, a component of the binary system HD 144208-9 (Sky and Telescope, August). The primary in the system is of class $G$ and the dwarf is of class $A$ and a normal object for its class. Its luminosity in terms of the primary was determined from the combined spectrum of the two stars, in which the metallic lines and the $K$ line of calcium are weaker than normal, and the wings of the Balmer hydrogen are stronger. The assumption that the primary obeys the mass-luminosity relation-mass proportional to absolute magnitude--made it possible to determine the masses and mean densities of both stars. Many other binary systems exist in which the components are $G$ - and $A$-type, and the investigation of these systems is important that more may be understood about the relationship of the sub-dwarfs to the white dwarfs.

\section{A Radio'ogical Library}

A RADIOLOGrCal library valued at $£ 3,500$ is on sale by the Museum Book Store, 45 Museum Street, W.C.1, by whom a 12-page pamphlet is issued. This world-wide collection of journals and periodical publications, each in the language of its origin, is not likely to be duplicated, and it is hoped that it will find its way into some research laboratory or radiological centre. The chief publishers of radiological subjects have been the United States, Germany, France and Great Britain, and we can think of no X-ray or radium journal which is not included in this library. This offer of sale has now been open for some months and the step of acquiring the valuable collection waits to be taken by some authority with vision as well as money.

\section{Prof. F. H. Garner}

THE chair of oil engineering and refining in the University of Birmingham, rendered vacant by the death of Prof. A. W. Nash, has been filled by the appointment of Dr. F. H. Garner, a graduate of the University (1914). Dr. Garner was for many years chief chemist of the Anglo-American Oil Co. and is that company's principal scientific officer in Great Britain; he has a high reputation and an excellent record as a research chemist in the field of oil chemistry. He has acted as an external examiner in the Oil Engineering Department of the University of Birmingham for several years and has thus a knowledge of the working of the Department.

\section{Announcements}

THE Emil von Behring prize, which is awarded by the University of Marburg every two years for outstanding achievements in immunology, serum therapy and chemotherapy, has been awarded to Prof. Paul Uhlenhuth, professor of hygiene and bacteriology in the University of Freiburg-im-Breisgau.

WE have received Abstracts of Articles and Patents on the Production of Glycerol by Fermentation published by the National Research Council of Canada, Ottawa, 1942, which contains abstracts of 109 articles and 114 patents on this subject. The publication is N.R.C., No. 1070 , price 50 cents. 